\title{
Diagnostic Algorithm for Superficial Venous Malformations in Newborns
}

\author{
Anca E. Chiriac ${ }^{1}$, Adrian Naznean², Cristian Podoleanu³ ${ }^{3}$ Simona Stolnicu4,5, Anca Chiriac $6,7,8$ \\ 1 “Gr.T. Popa” University of Medicine and Pharmacy, Iași, Romania \\ 2 University of Medicine and Pharmacy, Tîrgu Mureş, Romania \\ 3 Department of Internal Medicine, University of Medicine and Pharmacy, Tîrgu Mureş, Romania \\ 4 Department of Pathology, University of Medicine and Pharmacy, Tîrgu Mureş, Romania \\ 5 Histopat Invest Laboratory, Tîrgu Mureş, Romania \\ ${ }^{6}$ Department of Dermatology, Nicolina Medical Center, Iași, Romania \\ 7 Apollonia University, lași, Romania \\ 8 "P. Poni” Research Institute, Romanian Academy, Iași, Romania
}

\section{CORRESPONDENCE}

\section{Adrian Naznean}

Str. Gheorghe Marinescu nr. 38

540139 Tîrgu Mureş, Romania

Tel: +40744257684

E-mail: adinaznean@yahoo.com

\section{ARTICLE HISTORY}

Received: April 13, 2018

Accepted: July 28, 2018
Anca E. Chiriac • Str. Universitătii nr. 16, 700115 lași, Romania. Tel: +40 232301600

Cristian Podoleanu • Str. Gheorghe Marinescu nr. 1 , 540099 Tîrgu Mures, Romania. Tel: +40 744573784 E-mail: podoleanu@me.com

Simona Stolnicu • Str. Gheorghe Marinescu nr. 38 540139 Tîrgu Mureș, Romania. Tel: +40 265215551 Anca Chiriac • Str. Hatman Șendrea nr. 2, 700613 lași, Romania. Tel: +40332808703

\begin{abstract}
Superficial venous malformations can be clinically diagnosed since birth as localized, bluish or purple lesions, especially on the lower extremity, but deep venous malformations are difficult to diagnose only by clinical appearance. The diagnostic algorithm for superficial venous malformations in newborns includes clinical examination and Duplex ultrasonography. The latter allows differentiating tumors (hemangiomas) from vascular malformations and evaluating flow characteristics as well as localizing the site of the malformation.
\end{abstract}

Keywords: Duplex ultrasonography, vascular malformation

Superficial venous malformations are noticed since birth as localized, bluish or purple lesions, especially on the lower extremity. It is quite difficult to establish, by simple clinical examination, the deep location of the venous malformations. ${ }^{1}$

The diagnosis of vascular malformations is not easy; it starts with a meticulous anamnesis and clinical examination. Inspection of the involved area should reveal skin color changes (Figure 1A), edema, enlarged and/or asymmetric growth, ulcerations, superficial varicosities, signs of thrombophlebitis associated with other anomalies. Palpation is the next step of examination, revealing induration of the affected anatomical region and enabling recording the pulse. Auscultation of both arterial and venous systems can be of great help in establishing the type of vascular malformation. ${ }^{2}$ Arterial vascular malformations are more aggressive, with a hemodynamic and clinical impact on the involved area.

A dermatological diagnostic algorithm includes the criteria that define a localized venous malformation: well-delineated margins, anomalies restricted to tissue and fascia, with a clear delimitation from normal surrounding areas. 
TABLE 1. Differential diagnosis between arterial and venous malformations

\begin{tabular}{lll}
\hline & Arterial malformations & Venous malformations \\
\hline Inspection & Skin discoloration & Bluish, purple \\
Palpation & High local temperature & Normal local temperature \\
Auscultation & Bruit/thrill & Non-pulsation, no bruit, no thrill \\
Valsalva test (crying) & Negative & Positive (enlargement of the area) \\
Doppler ultrasonography & Fast-flow or high-flow & Monophasic, biphasic and no \\
& & detectable flow \\
\hline
\end{tabular}

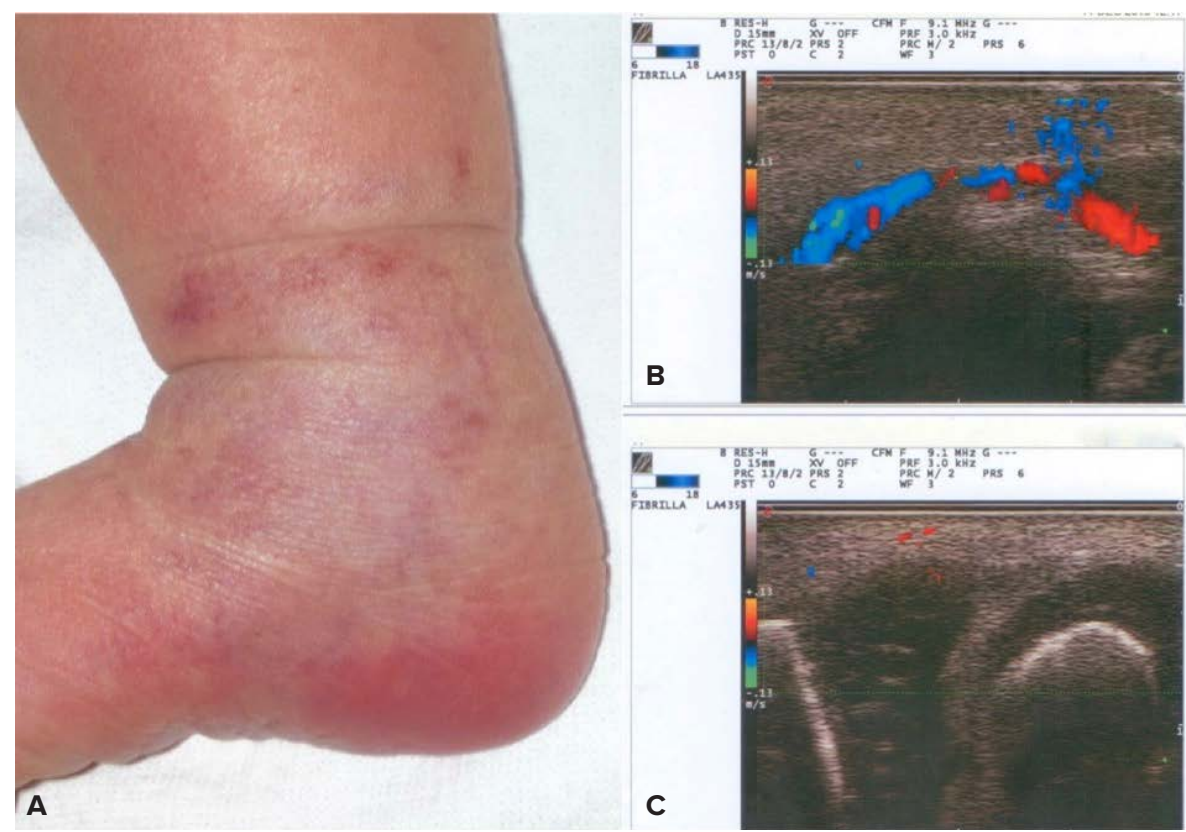

FIGURE 1. A - Localized, well-delineated bluish skin lesions in a male newborn involving the lower third of the leg; B - Color flow imaging highlighting a low-flow Doppler pattern (venous malformation); C - No bone or muscular involvement

Duplex ultrasonography is the first investigation for the noninvasive evaluation of patients with venous malformations. Duplex ultrasonography allows differentiating tumors (hemangiomas) from vascular malformations and evaluating flow characteristics (Figure $1 \mathrm{~B}, \mathrm{C}) .^{1-3}$

It is of paramount importance to distinguish, by clinical and imaging techniques, vascular malformations from tumoral lesions (hemangiomas), which are kept together under the same large umbrella of congenital vascular anomalies. Treatment modalities and long-term prognosis are different for arterial and venous malformations, respectively; therefore, a precise diagnosis is critical.

\section{CONFLICT OF INTEREST}

Nothing to declare.

\section{REFERENCES}

1. Lee BB, Bergan J, Gloviczki P, et al. Diagnosis and treatment of venous malformations. Consensus document of the International Union of Phlebology (IUP)-2009. Int Angiol. 2009;28:434-451.

2. Lee BB, Baumgartner I, Berlien HP, et al. Consensus Document of the International Union of Angiology (IUA)-2013. Current concept on the management of arterio-venous management. Int Angiol. 2015;34:97-149.

3. Yoshida $H$, Yusa $H$, Ueno E. Use of Doppler color flow imaging for differential diagnosis of vascular malformations: a preliminary report. $J$ Oral Maxillofac Surg. 1995;53:369-374 